LBL -27468

DE89 015338

\title{
THRESHOLD PHOTOELECTRON SPECTRUM OF THE ARGON 3s SATELLITES
}

L. J. Medhurst, A. Schach von Wittenau, R. D. van Zee, J. S. Zhang, S. H. Liu, and D. A. Shirley

Deparment of Chemistry, University of California and Materials and Chemical Sciences Division, Lawrence Berkeley Laboratory, I Cyciotron i sad, Berkeley, California 94720

\section{D.W. Lindle}

National Institute of Standards and Technologies, Gaithersiurg, Maryland 20899

\section{ABSTRACT}

Lavely a variety of techniques 1,2 have studied the electen correlation savellives with binding energies between the Argon 3s binding enerzy $(29.24-V)$ and the $2 p^{-2}$ ionization potential $(43.38 \mathrm{eV})$. One of these techniques, Threshold Phwoelectron Spectroscopy ${ }^{3}$. with $-90 \mathrm{meV}$ FWHM resolution, revealod at least 25 individual eloctronic states. All of these could contribute to any other savellite spectrum, and this belped explain some discrepancies between previous measurements. This technique has been applied to the same region with higher resolution ( $<60 \mathrm{meV}$ at the Ar $3 s^{-1}$ peak). In this higher resolution spectrum at least 29 individual electronic states are present. In some cases the multiplet splitting is observed.

\section{INTRODUCTION}

The Argon inner valence arellites have been studied, recently, by a variety of techniques with a variety of incident photon energies.1-6 By measuring the asymmetry parameter Adam et. al. ${ }^{1}$ showed that the lower binding energy satellites have symmetries other than $2 S$, and at $-40 \mathrm{eV}$ photon energy they also suw evidence for satellites with lower binding energies than had been seen in the preceding $X$-ray work. 7 Dther subsequent investigations 4,5 concentrated upon improving the resolution at higher incident photon energies. Each time the resolution improved more final states emerged. Two other ${ }^{3,6}$ studies of these satellites used intrinsically high resolution techniques. One ${ }^{6}$ used broad band synchrotron radiation and detected the dispersed fluorescent radiation from the excited states to the ground state of the ion; the other ${ }^{3}$ varied the incident photon energy of 
synchrotron radiation and detected $0 \mathrm{~V}$ electrons. Both of these rechniques revealed many new 3s satellites.

\section{EXPERIMENT}

In this paper we report another measurement of the argon $3 s^{-1}$ satellites region using the same technique as reference 3. In this case the FWHM of the argon $3 \mathrm{~s}^{-1}$ peak was less than $60 \mathrm{meV}$, which is an improvement of more than $30 \%$ over the previous measurement. The experiment was performed on the new grasshopper beamline at SSRL, using the $600 \mathrm{~V} / \mathrm{mm}$ grating. The experimentul apparatus has been described before.8,9 In this instance a $1000 \AA$ silicon window separated the ultra high vacuum $\left(10^{-10}\right.$ tor $)$ of the monochromator from the experimental chamber $\left(10^{-5}\right.$ torr). The amount of second order light was determined using the known cross section of neon $2 \mathrm{p}^{-1}$, and the cross sections of the satellites were corrected with this. The reported errors are statistical and do not reflect any error in this calibration procedure. The energy scale was calibrated using the $3 \mathrm{~s}^{-1}$ argon peak and setting it equal to 29.2,4eV.10 The uncertainty with the energy scale is \pm $0.02 \mathrm{eV}$ at the lower energies, but probably as high as $\pm 0.05 \mathrm{eV}$ close to the double ionization threshold.

\section{RESULTS}

Figure 1 contains the Zero Kinetic Energy spectrum of argon from 28.5 to $44.5 \mathrm{eV}$. It is apparent from the spectrum that the satelitites with lower binding energies are more prominent in the zero kinetic energy spectrum, in agreement with the results of Adam et. al. 1 The more congested region from 33.75 to $40.0 \mathrm{eV}$ is presented in Figure 2 with a finer point density than in Figure 1, and the resulis from these spectra are summarized in Table 1.

A comparison with the higher energy, high resolution work rif Brion et. al. 4 indicates that most of the satellites are present at all incident photon energies, with the exception being some of the lower binding energy quarut states, which are visibly present only at threshold. Some of these staves are almost degenerate in energy with doubly excited states of the type $3 s^{2} 3 p^{4} n 1$ n' 1,11 and it has been shown previously that they are enhanced on resonance. ${ }^{9}$ Recent work by Schartner et. $\mathbf{a l} .12$ showed that some of the doubly excited states decay intermediately to the $3 \mathrm{~s}^{-1}$ state. It then seems quite possible that some also, or altematively, decay through $3 s^{2} 3 p^{4}$ nl states.

One of the most notable features of this spectrum is that two ${ }^{2} \mathrm{P}$ states are well resolved into their individual $\mathrm{J}=1 / 2$ and $\mathrm{J}=3 / 2$ components. The intensity ratio $I 3 / 2 / I_{1} / 2$ is $4.5 \pm 1.0$ for the ${ }^{2} \mathrm{P}$ state with binding energies 32.90 and $33.02 \mathrm{eV}$ and $2.88 \pm 0.24$ for 
the 33.70 and $33.82 \mathrm{eV}$ peaks. This indicates that the ratio is greater than expected statistically in both cases. The error in the intensity, however, does not include possible systematic errors due to the correction for second order light. Therefore these relative intensities must be regarded as tentative.

\section{REFERENCES}

1. M. Y. Adam, P. Morin, a W W in, Phys. Rev. A 31,1426 (1985),

2. K. T. Leung and C. E. Brion, C.crss. Phys, 82, 87 (1983).

3. U. Becker, B. Langer, H. G. Kerkhoff, M. Kupsch, D. Szostak, R. Wehlitz, P. A. Heimunn, S. H. Liu, D. W. Lindle, T. A. Ferrett, and D. A. Shirley, Phys Rev. Lett. 60, 1490 (1988).

4. F. E. Brion, A. O. Bawagan, and K. H. Tan, Can., J. Chem. 66, 1877 (1988).

5. H. Kossman, B. Krtissig, V. Sciumidt, and J. E. Hansen, Phys. Rev. Lett. 58, 1620 (1987).

6. J. A. R. Samson, Y. Chung, and Eun-Mee Lee, Phys. Lett. A 127, 171 (1988).

7. D. P. Spears, H. J. Fishbecik, and T. A. Carlson, Phys. Rev. A 9, 1603 (1974).

8. M. G. White, R. A. Rosenberg, G. Gabor, E. D. Poliakoff, G. Thorton, S. H. Southworth and D. A. Shirdey, Rev. Sci. Instr. 50, 1268 (1979).

9. P. A. Heimann PhD Thesis, University of Califomia, Berkeley LBL 22219 (1987).

10. C. E. Moore,Atomic Energy Levels, NBS Special Publication No. 467 (U. S. GOP Washington, DC, 1969), Vol.1.

11. R. P. Madden D. L. Ederer, and K. Codling, Phys. Rev. 177, 136 (1969).

12. K. H. Schartener, B. Mobbus, P. Ienz, H. Schmoranzer, and M. Wildberger, Phys. Rev. Lett. 61, 2744 (1988).

Acknowledgement.

This work was supported by the Director, Orfice of Energy Research, Office of Basic Energy Sciences, Chemical Sciences Division of the U.S. Department of Energy under Contract No. DE-AC03-76SF00098. It was performed at the Stanford Synchrotron Radiation Laboratory, which is snpported by the Department of Energy's Office of Basic Energy Sciences. 
Figure Captions:

Fig 1. Zero linetic energy spectrum of argon from the 3 s threshold to the double ionization limit. Data points ire uncorrected for second order light. The smooth line is a least squares fit to the data.

Fig. 2. Zero kinetic energy spectrum of argon over the most congested region of fig. 1 (33.2 to $40.0 \mathrm{eV}$ ) with a finer point density. Data points are uncomected for second order light. The smooth line is a least squares fit to the data. 


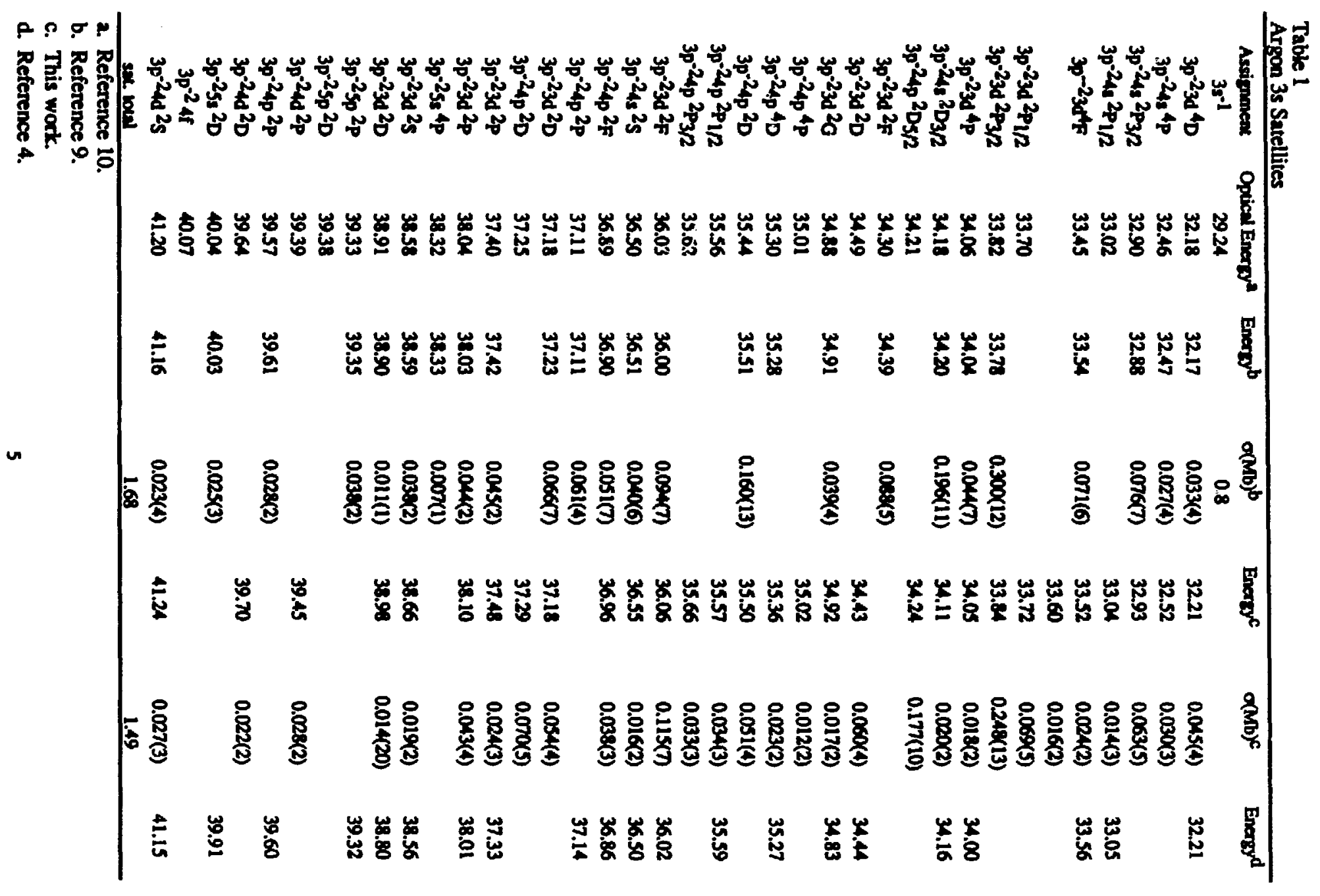




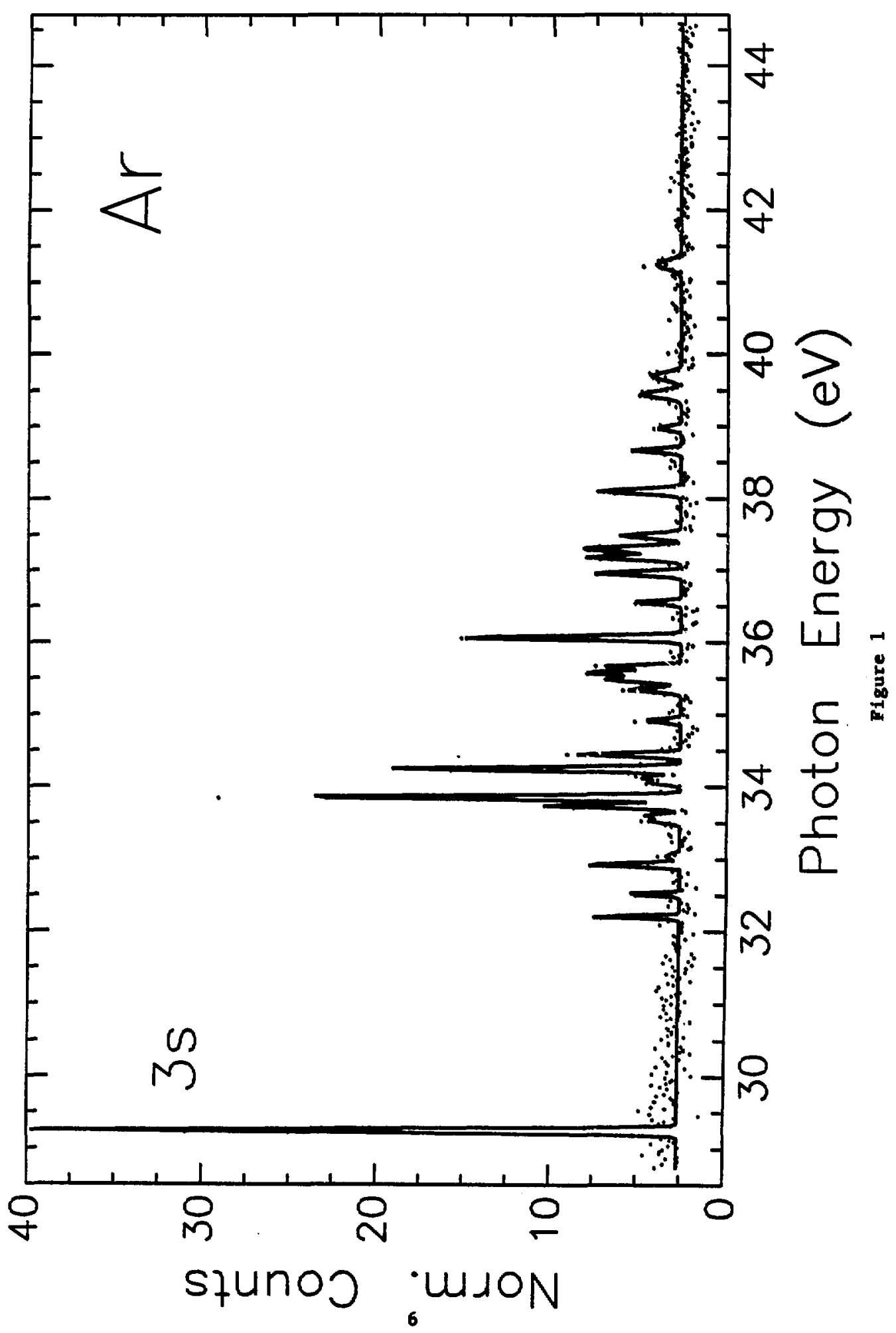




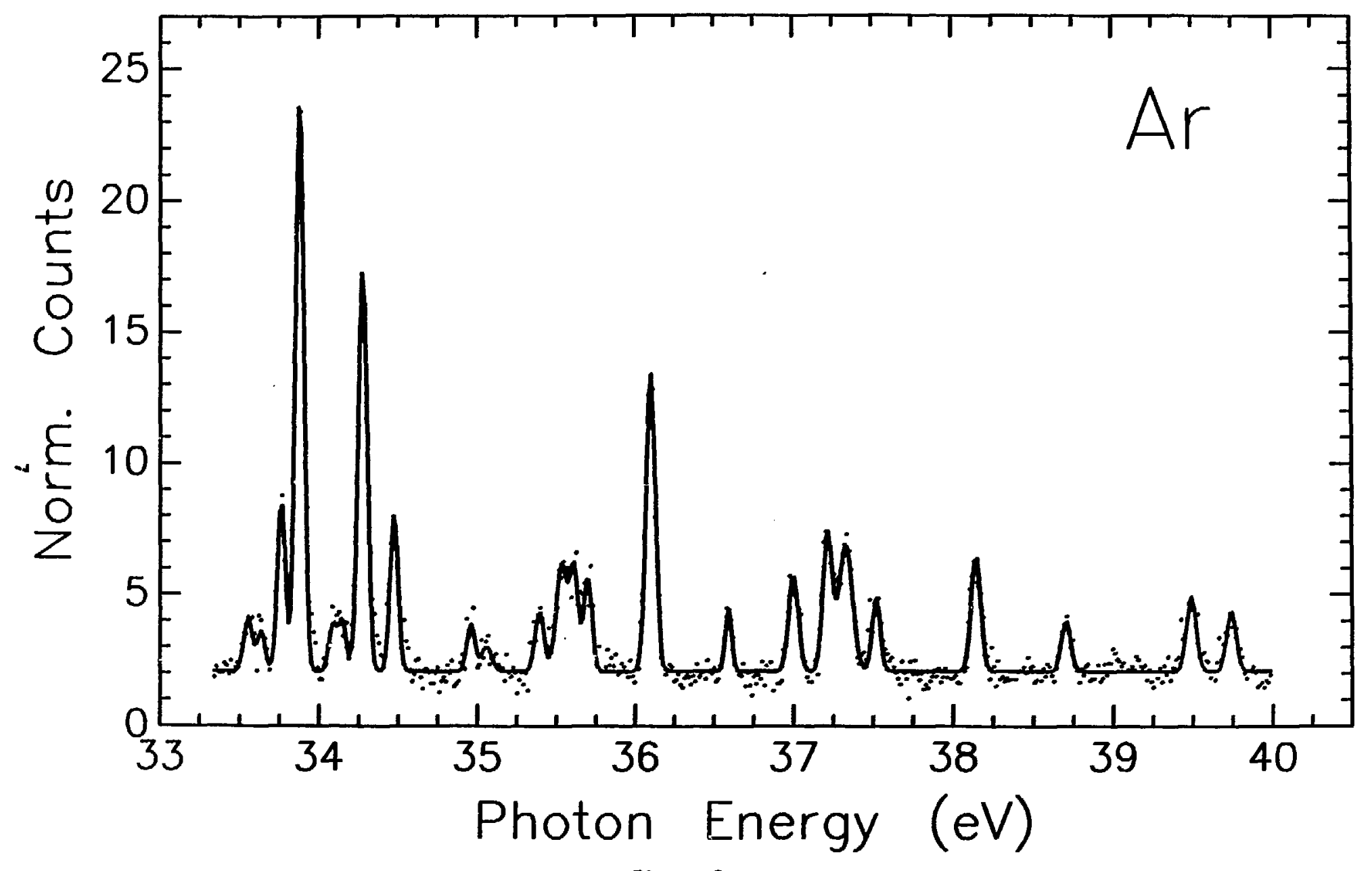

Figure 2 